\title{
Vegetables Consumption and its Benefits on Diabetes
}

\author{
João Carlos da Silva Dias ${ }^{1, *}$ and Saeko Imai ${ }^{2}$ \\ ${ }^{1}$ University of Lisbon - Instituto Superior de Agronomia, Tapada da Ajuda, 1349-017 Lisboa, Portugal \\ ${ }^{2}$ School of Comprehensive Rehabilitation, Osaka Prefecture University, Habikino-shi, Osaka 583-8555, Japan
}

\begin{abstract}
Vegetables are indispensable for equilibrated diets since they charge dietary fiber, phytochemicals, vitamins, and minerals. Each vegetable comprise a distinct amalgam and amount of these compounds, which differentiate them from other vegetables. Vegetable intakes has been highly correlated with improved gastrointestinal health, reduced risk of heart attack, some types of cancer and chronic ailments such as diabetes.

Type 2 diabetes is a lifestyle ailment. Our vegetables selection and amount of dietary fiber, phytochemicals, vitamins and minerals consumed can either prevent or promote diabetes. This article highlights the nutritional and health benefits of different vegetables and their dietary fiber, vitamin C, vitamin E, carotenoids, flavonoids, thiosulfides, magnesium, selenium, chromium, and zinc contents, to prevent and reverse diabetes. The proper order of eating vegetables before carbohydrate and its effect on postprandial blood glucose levels, and glycemic control is also discussed. Data shows that eating vegetables before carbohydrates is effective to reduce postprandial hyperglycemia in Type 2 diabetes patients, as well as in healthy people. So vegetables should be eaten before carbohydrates at every meal.
\end{abstract}

Keywords: Vegetables, dietary fiber, phytochemicals, resistant starch, Type 2 diabetes, glucose control, healthier life.

\section{INTRODUCTION}

Vegetables play a remarkable role in human nutrition and health since they charge dietary fiber, phytochemicals, vitamins, and minerals [1-3].

Until few years ago it was believed that 14 vitamins and 16 essential minerals were the key for human nutrition and health. Recently, with the developments in chemistry, it was found that vegetables contain thousands of beneficial phytochemicals in addition to the 14 vitamins and 16 minerals. Some phytochemicals are robust antioxidants and are believed to reduce the risk of some chronic ailments [3-7]. Phytochemicals are the key to best health as well as disease protection and regression. However, phytochemicals in freshly harvested vegetables may be thermal degraded and lost by processing techniques such as long steaming and cooking $[8,9]$, which reduce their concentration, and may inactivate hydrolytic enzymes.

Vegetable intake has been highly correlated with improved gastrointestinal health, and reduced risk of heart attack, some types of cancer and chronic ailments such as diabetes [2,3]. By those reasons a regular consumption of a vegetable rich diet has unquestionable positive effects on health and is likely to afford better protection against several chronic ailments. The mechanisms by which vegetables

*Address correspondence to this author at the University of Lisbon - Instituto Superior de Agronomia, Tapada da Ajuda, 1349-017 Lisboa, Portugal;

Tel: 00351.914137940; E-mail: mirjsd@gmail.com decrease risk of disease is largely unknown [2,3]. Different constituents of the whole food may contribute to the overall health benefit. For example the dietary fiber content contribute to the health benefit by improving bowel transit, by helping manage blood glucose concentrations, and by transporting through the human gut a remarkable amount of phytochemicals and minerals linked to the fiber matrix.

Diabetes (Diabetes mellitus) is a chronic ailment that arises when the pancreas does not produce enough insulin or when the body cannot efficaciously use the insulin (hormone that regulates blood sugar) it produces. Raised blood sugar (hyperglycemia) is a common consequence of uncontrolled diabetes [10]. Diabetes are of three main types: Type 1, Type 2, and gestational diabetes. Type 2 diabetes is the most common type worldwide. It is a chronic and lifestyle ailment.

In 2014, about 422 million adults worldwide had diabetes (that is 1 person in 11) [11], with more than $80 \%$ living in the middle- and low-income countries [12]. Asia alone hosts more than $60 \%$, predominantly type 2 diabetes [13]. Diabetes prevalence has been rising for the past 3 decades and will continue rising all over the world but more speedily in the middle- and low-income countries [11]. By 2025 a fifth of the world's diabetic patients will be Indian [12].

The greatest number of people with diabetes are between 40-59 years old, with 179 million people undiagnosed [12]. Diabetes is occurring increasingly in 
children and young adults and, in 2014, many youth aged under 18 years had diabetes [11].

Our vegetables selection and amount of dietary fiber, phytochemicals, vitamins, and minerals consumed can either prevent or promote diabetes [3]. This article highlights the nutritional and health benefits of different vegetables and the proper level of dietary fiber, vitamin $\mathrm{C}$, vitamin $\mathrm{E}$, carotenoids, flavonoids, thiosulfides, magnesium, selenium, chromium, and zinc contents, that should be consumed to prevent and reverse diabetes. The proper order of eating vegetables before carbohydrate and its effect on postprandial blood glucose levels, and glycemic control is also discussed.

\section{VEGETABLES AND NUTRITIONAL AND HEALTH BENEFITS}

A world survey showed that at least 402 vegetables are cultivated and commercialized worldwide [14,15]. They represent 69 families and 230 genera. From these great diversity leafy vegetables comprised $53 \%$ of the total, followed by fruits vegetable $(15 \%)$, and roots and tuber vegetables (17\%).

All the vegetables may provide defense to humans against chronic ailments. And there is a general sentiment among nutritionists that the nutrition and health benefit of vegetables should not be connected to only one form of vegetable. A balanced diet that includes more than one form of vegetable is liable to provide better nutrition and health protection, since it will ensure an adequate intake of dietary fiber, phytochemicals, vitamins, and minerals $[3,16,17]$.

With the exclusion of glucosinolates and thiosulfides (which are distinct phytochemicals of cruciferous and alliums, respectively), the phytochemicals, vitamins, and minerals content of a many vegetables lie principally in dietary fiber, folate, polyphenols (carotenoids, flavonoids), vitamin $\mathrm{C}$, and selenium $[2,3]$. The principal dissimilarity is that each vegetable family incorporate a distinct amalgam and amount of these bioactive compounds, which differentiate them from other vegetables $[2,17]$. For instance vegetables of the Apiaceae family (carrot, parsnip, celery, celeriac, fennel, parsley, coriander, etc.) are rich in flavonoids, carotenoids, vitamin $\mathrm{C}$, and vitamin $\mathrm{E}$. The vegetables of the Asteraceae or Compositae family (lettuce, chicory, stem lettuce, globe artichoke, etc.) are rich in flavonoids, tocopherols and conjugated quercetin. The Chenopodiaceae family vegetables (Swiss chard, spinach, garden beet, quinoa, etc.) are among those that are rich in oxalates $[18,19]$, but also excellent sources of dietary fiber, vitamins, calcium, manganese, flavonoids and carotenoids. The Cucurbitaceae family vegetables (e.g. squash, pumpkin, cucumber, melon, bitter gourd, etc.) are rich in carothenoids, tocopherols, and vitamin C [20]. All the legumes (Leguminosae or Fabaceae family; e.g. pea, bean, soy-bean, lentils, chickpea, etc.), mature and immature seeds are great sources of dietary fiber, resistant starch, protein, isoflavonoids [21], calcium and iron. Cruciferous vegetables (Cruciferae or Brassicaceae family) which include kales, collards, cabbages, Brussels sprouts, cauliflower, broccoli, kailan, Pak choi or Bok choi, Chinese cabbage, turnip, swede, watercress, radish, rocket, watercress, mustards, etc. are high sources of glucosinolates, as well as vitamin C, carotenoids, calcium, and can accumulate selenium. The vegetables of the Alliaceae family (onions, garlic, shallots, leek, Welsh onion, chives, etc.) are rich in thiosulfides, flavonoids, calcium, potassium, manganese, chromium and can accumulate selenium. Vegetables of the Solanaceae family that includes tomato, potato, sweet and hot peppers, eggplant, etc. are very diverse, in their contribution to bioactive compounds.

\section{DIABETES}

\subsection{Types}

As mentioned earlier diabetes are of three main types: Type 1, Type 2, and gestational.

Type 1 diabetes, named as juvenile or insulindependent diabetes, is differentiated by its deficiency in insulin production and demands daily administration of insulin, typically by injection. The cause of Type 1 diabetes is actually not perfectly known and it is not preventable. Today we only know that the damage of the insulin-producing cells occur due to the cells of the body's immune system that instead of protecting they attacked the cells of the pancreas destroying its ability to produce insulin. Nevertheless new research has revealed that diet and lifestyle can dramatically decrease the risk of Type 1 diabetes and their complications [22].

Type 2 diabetes, named as adult or non-insulindependent diabetes, is due to the body's ineffective use of insulin. Body produces insulin but cannot effectively use it. Type 2 is the most prevalent in the world (about 9 out 10 people with diabetes have type 2 diabetes). Reports of Type 2 diabetes in children that were previously rare, have increased worldwide. 
Gestational diabetes is different from previous ones and it is characterized by hyperglycemia only during pregnancy [23]. Women with gestational diabetes have increased risk of Type 2 diabetes in the future.

Diabetes is a major cause of blindness and vision loss [24], kidney failure [25], heart attacks and strokes [26], leg amputation and nerve damage [11], Alzheimer's disease and dementia [27-30]. In 2014, diabetes was the direct cause of 1.5 million deaths. WHO projects that diabetes will be the $7^{\text {th }}$ major cause of death in 2030 [12].

Typical Type 2 diabetes is caused by unhealthy diet and physical inactivity, which leads to overweight or obesity. Higher body circumference and Body Mass Index (BMI) are usually correlated with increased risk of type 2 diabetes, although this relationship may vary in different populations [11]. For instance Asians develop diabetes at lower degrees of obesity and at younger ages. Asians are known to have more fat per BMI unit which contributes to increased insulin resistance [13]. Among the 3 major Asian populations, Indians have substantially higher level of insulin resistance, followed by intermediate levels in Malays, and the lowest level in Chinese population $(p<0.001)$ [13]. Over a fifth of China's adult population is overweight.

\subsection{Diabetes Tests and Screening}

The three main diabetes tests and screenings are: blood glucose, hemoglobin A1c, and Continuous Glucose Monitoring system (CGMs).

The blood glucose test determines the amount of glucose in a sample of blood. The blood glucose test may be used to monitor glucose levels and to detect hyperglycemia and hypoglycemia, in people diagnosed with diabetes. The test is usually done after fasting (not eating anything for at least 8 hours) but can be done at any time of the day. It is carried out using a blood sample taken from a finger or from the arm. In the market there are blood glucose meters that allow people to do their blood glucose tests at home. It involves pricking the side of a finger with a fingerpricking device and putting a drop of blood on a testing strip.

The fasting blood glucose level values for a normal person without diabetes is 70 to $108 \mathrm{mg} / \mathrm{dl}(=3.9$ to 6 $\mathrm{mmol} / \mathrm{l}$ ); for a pre-diabetic is 108 to $125 \mathrm{mg} / \mathrm{dl}$ ( $=6$ to 7 $\mathrm{mmol} / \mathrm{l}$ ); and for a diabetic patient is higher than 125 $\mathrm{mg} / \mathrm{dl}$ (> $7 \mathrm{mmol} / \mathrm{l}$ ). Blood sugar levels for those without diabetes should be below $7 \mathrm{mmol} / \mathrm{L}(125 \mathrm{mg} / \mathrm{dl})$.

The hemoglobin $\mathrm{A} 1 \mathrm{c}$ test $(\mathrm{HbA} 1 \mathrm{c})$ is a better test than blood glucose, that shows how well the diabetes is being disciplined. It measures the amount of glucose that is being carried by the red blood cells/hemoglobin. Measuring $\mathrm{HbA} 1 \mathrm{c}$ physicians are able to get a general panorama of what the average blood sugar levels have been over a 3 months period.

For people without diabetes, the normal range for the hemoglobin A1c test is between $4 \%$ and $5.7 \%$ (= 20 to $40 \mathrm{mmol} / \mathrm{mol}$ ). Hemoglobin A1c levels between $5.7 \%$ and $6.4 \% \quad(=40$ to $45 \mathrm{mmol} / \mathrm{mol})$ indicate increased risk of diabetes (pre-diabetes), and levels higher than $6.4 \%$ (> $45 \mathrm{mmol} / \mathrm{mol}$ ) indicate diabetes. The aim for patients with diabetes is to have hemoglobin A1c levels less than $7 \%$.

CGMs is a device that uses a tiny sensor placed under the skin of the belly of the patient. It measures the amount of glucose in the fluid inside the body. A transmitter on the sensor then sends the information to a wireless-pager-like monitor that the patient can for example clip on its belt. The sensor continuously checks the glucose levels whether they are highs or lows. Glucose reading is done every 5 minutes. It tracks the glucose levels throughout the day displaying for instance the effect of foods and exercise on glucose levels. So a CGMs is able of detecting hypoglycaemia and hyperglycaemia that may be undetected by selfmonitoring blood glucose and $\mathrm{HbA1c}$ tests [31].

\section{VEGETABLES AND DIABETES}

\subsection{Vegetable Bioactive Compounds}

The vegetable bioactive compounds usually associated to the reduction or reversion of Type 2 diabetes are dietary fiber, resistant starch, vitamins $C$ and E, carotenoids, flavonoids, thiosulfides, magnesium, selenium, chromium, and zinc.

Dietary fiber is very important since it works to keep blood-sugar levels stable and transport through the human gut an important amount of carotenoids and polyphenols coupled to the fiber matrix [2,3]. Dietary fiber is grouped into soluble and insoluble fiber. Soluble fiber retards gastric emptying, slows the glucose absorption, and is entirely or partly fermentable in the large intestine [32]. Soluble fiber it is very important for diabetics, as it slows the glucose absorption $[2,3]$. Insoluble fiber is important too, and health benefits 
include shortening of the bowel transit time and softer feces.

Resistant starch is the starch that it is resistant to stomach acid and digestive enzymes. It escapes digestion in the small intestine but passes to the large intestine, where it goes through fermentation by bacteria in the colon. It acts like a fiber too. It supplies few calories, and most of the calories do not raise glucose levels. When the bacteria in the bowel degrade the resistant starch it forms new compounds that have health benefits and beneficial effects for diabetics $[3,17,22]$.

Eating vegetables with dietary fiber and resistant starch will reduce hunger and appetite and for diabetics it is critical for lowering insulin requirement for starch digestion.

Vitamins $\mathrm{C}$ and $\mathrm{E}$ have been inversely associated with diabetes since they are antioxidants that overcompensate the endothelial dysfunction and glutathione level to normalize blood glucose pressure that occurred in diabetic patients with hyperglycemia $[3,17]$.

Carotenoids such as $\alpha$ - and $\beta$-carotene, lycopene, lutein, zeaxanthin, and $\beta$-cryptoxanthin, have a protective effect against progress of diabetes by relieving oxidative stress that interferes with the glucose uptake by cells $[3,17]$.

Flavonoids such as anthocyanins, flavonols, flavones, isoflavonoids, and syringic acid are associated with diabetes since their intake was observed to reduced type 2 diabetes risk.

Thiosulfides decrease blood glucose level by stimulating insulin secretion by the pancreas.
Magnesium is important since insulin secretion and function requires magnesium. It helps to regulate blood sugar. It is also the relaxation mineral.

Selenium is also important, but high selenium levels may contribute to diabetes $[3,17]$.

Chromium is an insulin cofactor that helps insulin work better, since it helps the hormone escort glucose from the blood-stream into cells. Diabetic-promoting diets are low in chromium. Eating refined grains, sweets, and processed foods leads to chromium deficiency and worsens diabetes.

Zinc is necessary for the production of insulin which regulates blood sugar levels and interacts also with other nutrients $[3,17]$.

\subsection{ANDI and Vegetables with Anti-Diabetic Properties}

ANDI (Aggregate Nutrient Density Index) is a scoring system based on nutrient content, rated on a 1 1,000 scale, that was established by Dr. Fuhrman [33]. This index are scores attributed to a variety of vegetables (and other foods) based on how many nutrients they deliver to our body in each calorie consumed. It was calculated by evaluating the content of dietary fiber, vitamins, minerals, phytochemicals, antioxidant capacities, etc. It is an index that estimates the nutritional quality of vegetables. It guides on increasing the nutrient density of the diet. The higher the ANDI score, and the greater percentage of those vegetables in the diet, the better our health and the probability of reversing the diabetes. Table 1 presents the highest ANDI scores in green vegetables.

Three main vegetable families are shown in this table: Brassicaceae (kale, collard greens, mustard

Table 1: List of Identified Green Vegetables with High ANDI Scores

\begin{tabular}{|c|c|c|c|}
\hline Vegetable & ANDI & Vegetable & ANDI \\
\hline \hline 1. Kale & 1000 & 9. Chinese cabbage & 714 \\
\hline 2. Collard greens & 1000 & 10. Brussels sprouts & 672 \\
\hline 3. Mustard greens & 1000 & 11. Arugula/Rocket & 12. Lettuce, green leaf \\
\hline 4. Swiss chard & 1000 & 13. Chicory & 585 \\
\hline 5. Turnip greens & 1000 & 14. Romaine lettuce & 510 \\
\hline 6. Watercress & 1000 & 15. Cabbage & 481 \\
\hline 7. Bok choi/Pak choi & 865 & 16. Broccoli rabe & 455 \\
\hline 8. Spinach & 739 & & \\
\hline
\end{tabular}


Table 2: List of Non-Green Vegetables with High ANDI Scores

\begin{tabular}{|c|c|c|c|}
\hline Vegetable & ANDI & Vegetable & ANDI \\
\hline \hline 1. Radish & 502 & 7. Cauliflower & 315 \\
\hline 2. Turnip & 473 & 8. Rutabaga & 296 \\
\hline 3. Carrots & 458 & 9. Bell pepper, Red & 265 \\
\hline 4. Acorn/Winter squash & 444 & 10. Bell pepper, Green & 11. Artichoke \\
5. Bell pepper, Yellow/Orange & 371 & 12. Asparagus & 244 \\
\hline 6. Kohlrabi & 352 & 234 \\
\hline
\end{tabular}

greens, turnip greens, watercress, pak choy, Chinese cabbage, Brussels sprouts, rocket, cabbage and broccoli rabe), Chenopodiaceae (Swiss chard and spinach) and Asteraceae (green leaf lettuce, chicory and Romaine lettuce). The highest ANDI scores of nongreen vegetables are presented in Table 2.

Table 2 also shows other Brassicaceae like radish, turnip, kohlrabi, cauliflower, and rutabaga. Different vegetables from various families are also shown as well as differences among the peppers, where orange pepper is better than the red and red better than the green pepper.

Leafy vegetables thus have the highest ANDI scores compared to other vegetables. They are highnutrient and low glycemic load vegetables. Leafy vegetables are rich in dietary fiber, carotenoids, vitamin $\mathrm{C}$, vitamin $\mathrm{E}$, flavonoids, calcium, magnesium, etc. All the leafy-green vegetables are good sources of magnesium because they have chlorophyll. An actual meta-analysis set up that greater leafy-green vegetables consumption was correlated to $14 \%$ decrease in risk of Type 2 diabetes [34]. An earlier research reported that each daily serving of leafy-green vegetables generates a $9 \%$ decrease in risk of Type 2 diabetes [35].

The leafy vegetables with high ANDI scores are Brassicaceae. They have dietary fiber and are a rich source of glucosinolates and other phytonutrients, and have a very high content in calcium and $\beta$-carotene. They are excellent sources of lutein and can also accumulate selenium.

Khan et al. [36] showed that oral feeding of regular rats for 60 days with a $B$. juncea diet $(10 \% \mathrm{w} / \mathrm{w})$ led to significant hypoglycemic effect. This result was associated to the positive stimulation of glycogen synthetase and to the suppression of glycogen phosphorylase and some other gluconeogenic enzymes.
Another important family is Chenopodiaceae. A recent research has shown that Swiss chard leaves contain at least 13 distinct polyphenol antioxidants [37] comprising the flavonoids kaempferol and syringic acid that have blood sugar regulating properties [37-39]. Syringic acid was demonstrated to inhibit the activity of the enzyme $\alpha$-glucosidase. When $\alpha$-glucosidase gets inhibited, fewer carbohydrates are converted to sugars and blood sugar is able to remain more steady [40]. Beet leaves have the same properties, since beet and Swiss chard are both from the Chenopodiaceae family, and are a unique source of the bioactive antioxidants named betalains. Nine betacyanin pigments where identified in the reddish-purple stems and veins of the leaves of Swiss chard and beet [41]. In the Swiss chard's yellowish stems and veins 19 betaxantin pigments, including histamine-betaxantin, alaninebetaxantine, tyramine-betaxantine, and 3methoxytyramine-betaxantin were identified [41]. Yoshikawa et al. [42], in an oral glucose tolerance test (OGTT) conducted in rats, that measures the body's ability to metabolize glucose [43], observed that several glycosides isolated from the root extract of beet increase glucose tolerance.

In Asteracea, lettuces and chicories are the main vegetables used in raw salads. Leaf and Romain lettuces have higher ANDI scores (585 and 510 respectively) than iceberg lettuce (127). Besides the nutritive and diabetic value of leaf and Romaine lettuce are higher than head lettuces (butter and batavia). They have more dietary fiber, minerals, vitamins, and phytochemicals. Raw vegetables are the healthiest food we can eat since some phytochemicals are only available if we eat the vegetables raw.

In the non-green vegetables we have after radish and turnip (both Brassicaceae) the carrots. Carrots are not a negative vegetable, even for the diabetic, because they are low in calories, nutrient rich, have fiber, and their glycemic load (GL) is only 3. Carrots 
when they are eaten raw their glycemic effect is lessened further as the body does not absorb all of the calories in the raw food. Recent research advocate that orange carrot with $\alpha$ - and $\beta$-carotene (vitamin A-rich carotenoids) might help diabetics [44,45]. Purple carrots, rich in anthocyanins (flavonoids) and low in carotenoids, were also recently associated with reduction in impaired glucose tolerance [46].

Another important non-green vegetable is potato. In general, potato is only associated as a source of carbohydrates. But it is also an excellent source of essential amino acids (such as lysine) and other bioactive compounds. In addition to superior quality proteins, potato tubers also have significant amounts of vitamins and minerals, as well as phytochemicals (phenolics, phytoalexins, etc.), and protease inhibitors [2]. There are yellow, red, and purple fleshed potato varieties with high content of phytochemicals though some varieties are known to have lower levels [1-3]. Other bioactive antioxidants presented in potato tubers include $\alpha$-tocopherol, lutein, $\beta$-carotene, folates and selenium [2].

A good alternative to potato for diabetic patients are kohlrabi and rutabaga which are of the Brassicaceae family. They are not starchy as potato, and have higher ANDI scores. Both can be eaten raw and when sliced they do not produce discoloration (no oxidation as in potato).

Other two families very important for diabetics are Alliaceae, Curcubitaceae and Leguminosae since they include several vegetables with anti-diabetic properties.

Consumption of Alliaceae are necessary of a diabetes prevention (or reversal). Garlic lowers blood sugar levels in diabetic patients [47] and administration of S-methyl cysteine sulfoxide isolated from onion restrained blood glucose and showed significant hypoglycemic effect in rats $[2,17]$. Onions and other Alliaceae also contain chromium that is linked to diabetes prevention by enhancing insulin receptor kinases [48]. Clinical surveys on diabetic patients showed that chromium can decrease fasting glucose, ameliorate glucose tolerance and bring down insulin levels. Swamy et al. [47] observed in some varieties that $200 \mathrm{~g}$ of onions contain chromium up to $20 \%$ of the daily requirements.

For Curcubitaceae, bitter gourd (Momordica charantia) has been intensively studied for its antidiabetic attributes. Different studies reported hypoglycemic and anti-hyperglycemic properties of bitter gourd [47,49-51]. Clinical surveys on diabetic patients using pulp and juice extracts of bitter gourd were reported to bring down serum insulin levels, to lower fasting blood glucose levels, and to ameliorate glucose tolerance [52]. Vicine, charantin and polypeptide-p are the principal hypoglycemic bioactive compounds from bitter gourd [53]. But there are also carotenoids ( $\beta$-carotene, lutein, and zeaxanthin), triterpenoids (momordicin), alkaloids and saponins, responsible for their side effect on glycemic control [54]. Momordicin possess insulin-like activity [55].

Besides bitter gourd other non-sweet Curcubitaceae that have anti-diabetic properties are ivy gourd (Coccinia grandis), snake gourd (Trichosantes cucumerina), and ridge gourd (Luffa acutangula). Immature fruits of ivy gourd have anti-hyperglycemic properties since they help regulate blood sugar levels [56]. In India they are used to prevent or treat diabetes [56]. Bioactive compounds in the ivy gourd inhibit glucose-6-phosphatase [47], a liver enzyme involved in the regulation of sugar metabolism. Snake gourd is also considered to be useful in treating Type 2 diabetes [47]. Ridge gourd contain insulin like peptides, and alkaloids that help to lower fasting blood glucose levels $[47,50]$.

In Leguminosae consumption of the legumes is correlated to reduced risk of Type 2 diabetes since they are the ideal carbohydrate source $[3,33,57]$. They are low in $\mathrm{GL}$ due to their moderate protein and abundant dietary fiber and resistant starch (that is fermented by bacteria in the colon). The chemical composition of legumes show decreases in calories that can be absorbed which contribute to the control of blood sugar levels.

\section{EFFECT OF EATING VEGETABLES BEFORE CARBOHYDRATES ON GLYCEMIA}

Figure 1 shows a Continuous Glucose Monitoring (CGM) data, of one patient with Type 2 diabetes (T2D), after eating carbohydrates before vegetables and after eating the reverse regimen. When the patient ate carbohydrates before vegetables, we can see values of the postprandial hyperglycemia of 360,320 , and 340 $\mathrm{mg} / \mathrm{dl}$; and also hypoglycemia before the meal. When the patient ate vegetables before carbohydrates, postprandial hyperglycemia was decreased, and no hypoglycemia was observed.

Imai et al. [58] studied whether eating vegetables before carbohydrates could reduce the daily 


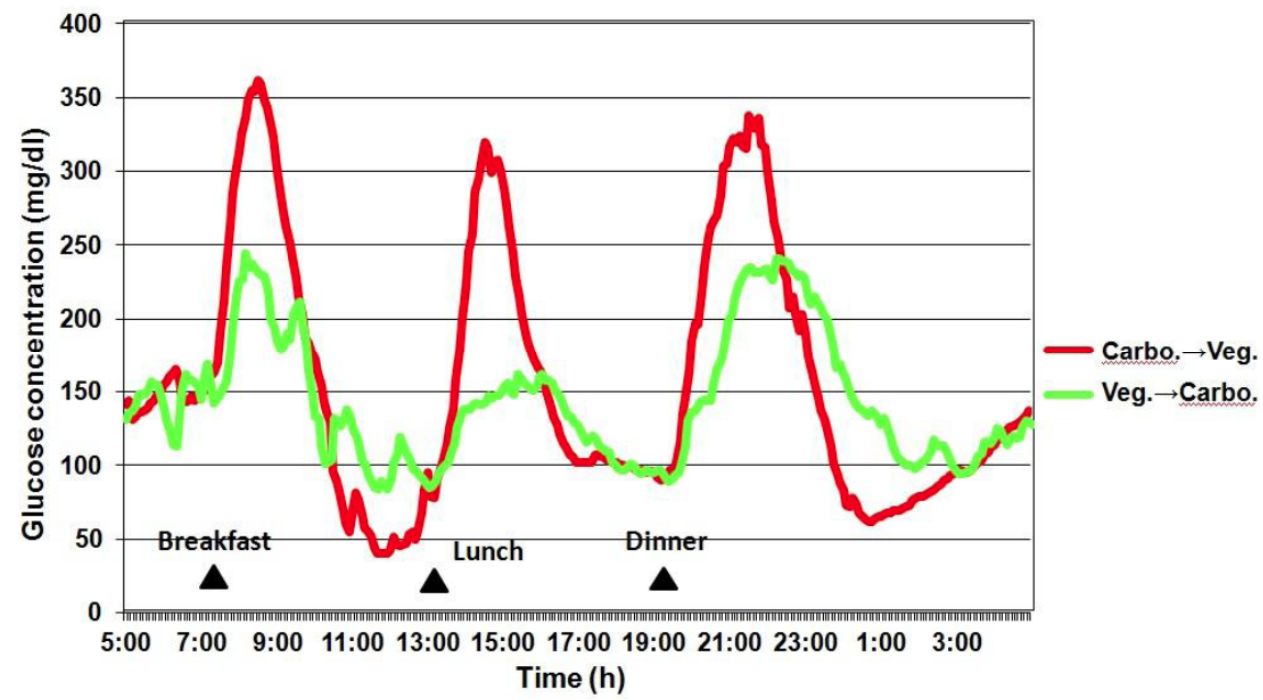

Figure 1: CGM data of a patient with Type 2 diabetes (T2D) after eating carbohydrates before vegetables and the reverse regimen.

postprandial glucose excursions measured by a CGM system in 19 Japanese outpatients with T2D $(\mathrm{HbA} 1 \mathrm{c}=7.2 \pm 1.0 \%$; and Fasting Blood Glucose $(F B G)=8.06 \pm 2.67 \mathrm{mM} / \mathrm{l})$ and 21 participants with Normal Glucose Tolerance (NGT); normal persons without diabetes $(\mathrm{HbA} 1 \mathrm{c}=5.4 \pm 0.6 \%$; and $\mathrm{FBG}=4.89 \pm 0.50 \mathrm{mM} / \mathrm{l}$ ). All these 40 subjects (in a randomized design) were allotted to a CGM system for 72 hours and eating test vegetable meals before and after carbohydrates meals on the second and third day.
The test meals, that possessed 21 grams of dietary fiber and $125.6 \mathrm{~kJ}^{\mathrm{kg}}{ }^{-1}$ per day, consisted of 500 grams of vegetables, meat or fish as the main dish, and rice or bread as carbohydrates.

Figure 2 presents the mean of the daily glucose values in the 19 outpatients with T2D and the 21 participants with NGT after eating carbohydrates before vegetables, and after the vegetable meal. The results show a significantly reduction in glucose profile when the subjects ate vegetables before carbohydrates

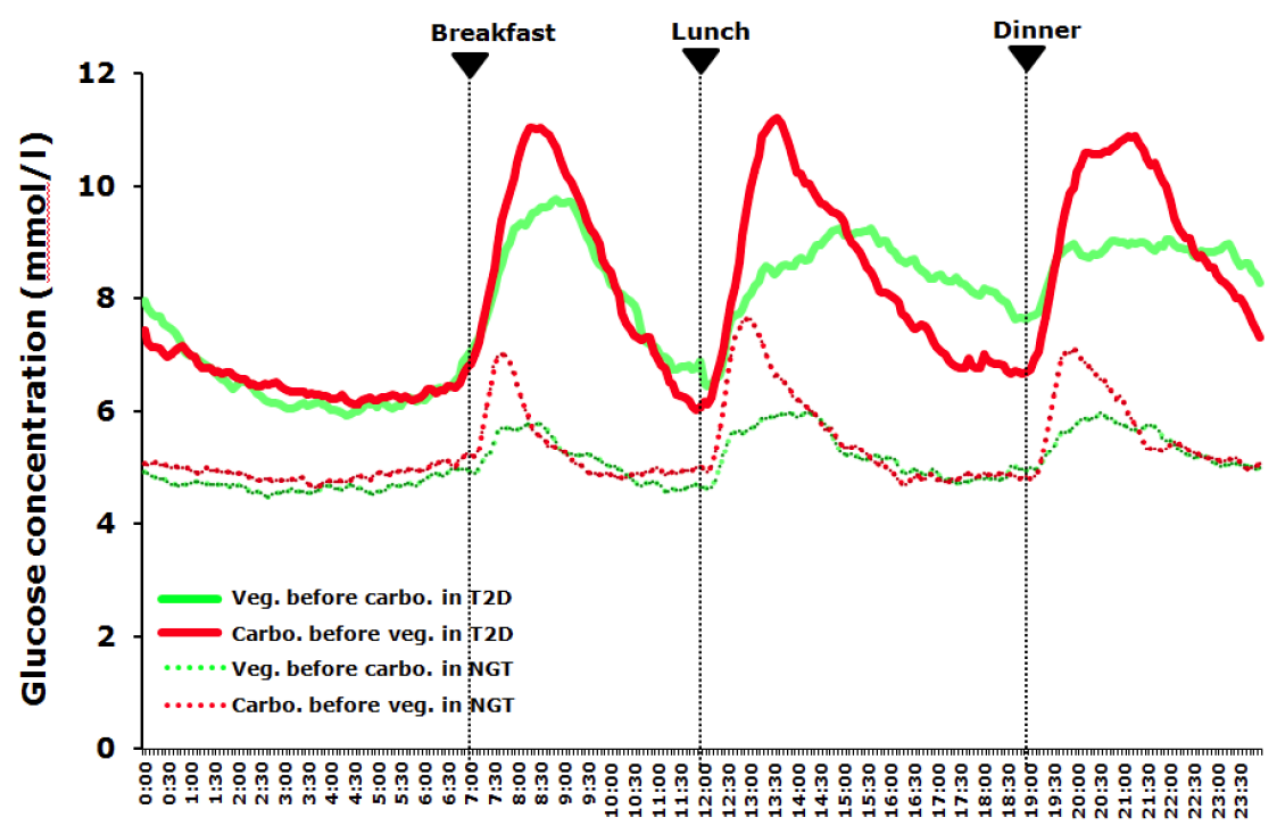

Time (h)

Figure 2: Effect of eating vegetables before carbohydrates on glucose concentration of 19 outpatients with T2D and 21 NGT participants. Mean of the daily glucose values in the T2D outpatients and in the NGT participants after eating carbohydrates before vegetables, and the reverse regimen. 


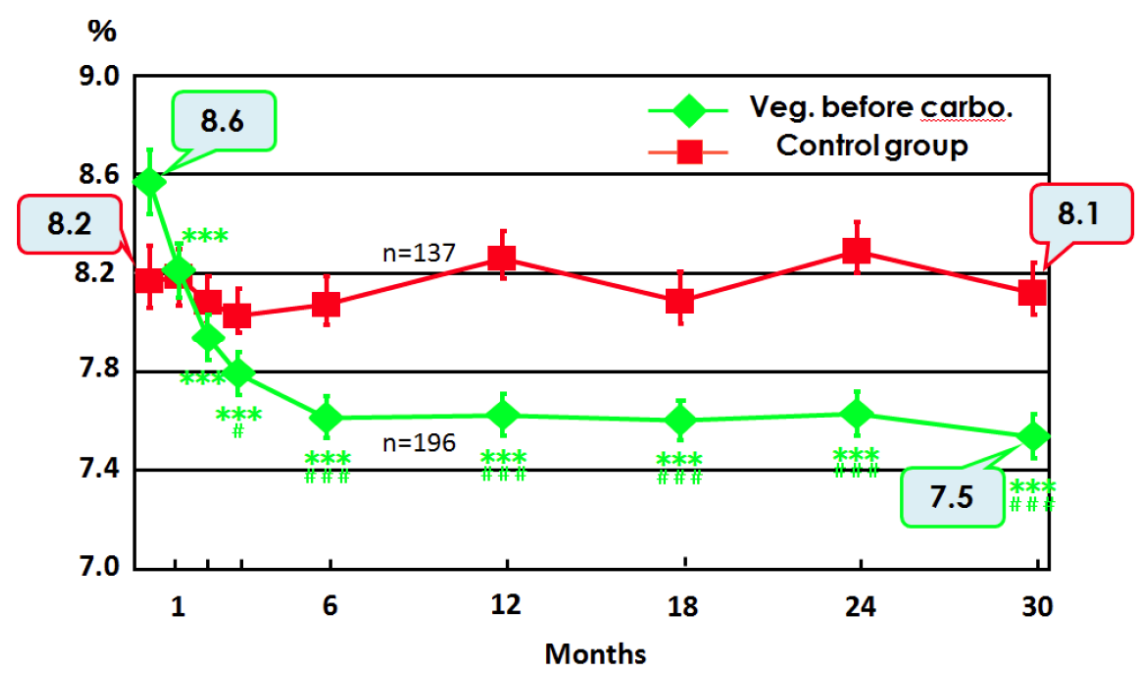

Figure 3: Effect of eating vegetables before carbohydrates on long-run screening of glycemic control. Study carried out during 30 months (2,5 years) in two study groups of outpatients with T2D: educational ( $n=196)$, eating vegetables before carbohydrates, and the control. It was evaluated variance in $\mathrm{HbA} 1 \mathrm{c}$ (NGSP \%). Baseline vs. after intervention (months): ${ }^{* *}=$ $p<0.001$. Educational (Veg. before carbo.) vs. the control group: $\#=p<0.05, \# \# \#=p<0.001$.

compared to when it was consumed after in patients with T2D and NGT participants.

In another research, only with outpatients with T2D, Imai et al. [59] examined if instructing these diabetic patients to eat vegetables before carbohydrates was effective on a long-run screening (30 months) of glycemic control (Figure 3). They examined changes in HbA1c (NGSP-\%) in outpatients with T2D as the main outcome. A total of 333 patients were distributed into two study groups: one educational $(n=196)$ that received operating instructions and a brochure about eating vegetables before carbohydrates; and a control $(n=137)$ who received only a checkup by a physician.

Improvements in $\mathrm{HbA} 1 \mathrm{c}$ levels over 30 months were maintained from 8.6 to $7.5 \%$ (NGSP\%) with the educational group ( $p<0.001)$ while no modifications were observed with the control (8.2 to $8.1 \%$ ), and $\mathrm{HbA1c}$ levels in the educational were significantly lower than the control after 3 to 30 months of the survey $[58,60]$.

The main reason for the decrease of postprandial blood glucose levels by eating vegetables before carbohydrates was due to consumption of dietary fiber present in the vegetables which allows carbohydrates consumed after vegetables to be digested slowly and so requiring less insulin [61]. Besides vegetables consumed before might have stimulate gastrointestinal incretin hormones (glucagon-like peptide-1 and glucose-dependent insulinotropic polypeptide). secretion, which contributes to the reduction in glycemic values [62], because they release insulin from the pancreas after carbohydrate ingestion and so they are essential in maintaining normal levels of glucose in the blood.

\section{CONCLUSIONS}

All the vegetables may provide protection to humans against chronic ailments. A balanced diet that incorporates a diversity of vegetable is likely to offer better protection to diabetes since each vegetable contains a distinct amalgam of phytochemicals, vitamins, and minerals.

Increased consumption of all leafy-green vegetables is associated to a decrease risk of Type 2 diabetes since they have dietary fiber and they offer many phytochemicals, vitamins and minerals to our body. Other non-green and non-starchy vegetables that are also rich in dietary fiber, and bioactive compounds also keep blood glucose low. Raw vegetable salads should be eaten in large quantities at the beginning of each main meal. Raw vegetables are better anti-diabetic foods than the cooked or processed since phytochemicals may be degraded by cooking and long steaming, due to thermal degradation and inactivation of the hydrolytic enzymes.

Both starchy and non-starchy vegetables are important for our diet. Legumes are a good carbohydrate source due to their protein, dietary fiber and resistant starch content. Vegetable fruits rich in fiber and antioxidants are also excellent vegetables for diabetics if sugar levels are low. Some cucurbits like bitter gourd, ivy gourd, snake gourd, and ridge gourd 
are recommended and considered useful for Type 2 diabetes.

Consuming vegetables before carbohydrates is effective to reduce postprandial hyperglycemia (and less hypoglycemia) in Type 2 diabetes patients. So Type 2 diabetes patients should eat vegetables before carbohydrates. This recommendation is also applicable to healthy people in order to prevent the onset of diabetes. Eating vegetables before carbohydrates is therefore the new concept instead of encouraging carbohydrate restrictions.

\section{REFERENCES}

[1] Dias JS, Ryder E. World vegetable industry: production, breeding, trends. Hort Rev 2011; 38: 299-356.

[2] Dias JS. Major classes of phytonutriceuticals in vegetables and health benefits: A Review J Nutr Therap 2012; 1: 31-62.

[3] Dias JS. 1. Vegetable breeding for nutritional quality and health benefits. In: Carbone $\mathrm{K}$, editor. Cultivar: chemical properties, antioxidant activities and health benefits. Nova Science Publishers, Inc., Hauppauge, New York. 2012; p. 181.

[4] Craig W, Beck L. Phytochemicals: health protective effects. Can J Diet Pract Res 1999; 60: 78-84.

[5] Herrera E, Jimenez R, Aruoma Ol, et al. Aspects of antioxidant foods and supplements in health and disease. Nutr Rev 2009; 67(1): S140-S144. https://doi.org/10.1111/j.1753-4887.2009.00177.x

[6] Wargovich MJ. Anticancer properties of fruits and vegetables. HortScience 2000; 35: 573-575.

[7] Southon S. Increased fruit and vegetable consumption within the EU: Potential health benefits. Food Res Int 2000; 33: 211-217.

https://doi.org/10.1016/S0963-9969(00)00036-3

[8] Verkerk R, Knol JJ, Dekker M. The effect of steaming on the glucosinolate content in broccoli. Acta Hort 2010; 867: 37-45. https://doi.org/10.17660/ActaHortic.2010.867.3

[9] Palermo M, Pellegrini N, Fogliano V. The effect of cooking on the phytochemical content of vegetables. J Sci Food Agric 2014; 94(6): 1057-1070 https://doi.org/10.1002/jsfa.6478

[10] WHO (World Health Organization). Definition, diagnosis and classification of Diabetes mellitus and its complications. Part 1: Diagnosis and classification of Diabetes mellitus. World Health Organization, Report Number: WHO/NCD/NCS/99.2. WHO, Geneva; 1999

[11] WHO (World Health Organization). Global report on diabetes. WHO, Geneva; 2016.

[12] Hoang TD. Prevalence of diabetes mellitus in the world and updates of diabetes care 2015. BIT's 4th Annual World Congress of Diabetes-2015, Kaohsiung, Taiwan 2015; p. 220

[13] Baruah MP. Type 2 diabetes in Asia population: regional similarities, differences and challenges in patient care. BIT's 4th Annual World Congress of Diabetes-2015, Kaohsiung, Taiwan 2015; p. 222.

[14] Kays SJ, Dias JS. Common names of commercially cultivated vegetables of the world in 15 languages. Economic Botany 1995; 49(2): 115-152.

https://doi.org/10.1007/BF02862917

[15] Kays SJ. Cultivated Vegetables of the World: A Multi-lingual Onomasticon. Wageningen Academic Publishers, The Netherlands; 2011.
Dias JS. Plant breeding for harmony between modern agriculture production and the environment. Agricultural Sciences 2015; 6: 87-116. https://doi.org/10.4236/as.2015.61008

[17] Dias JS. Nutritional quality and health benefits of vegetables: a review. Food Nutr Sci 2012; 3: 1354-1374. https://doi.org/10.4236/fns.2012.310179

[18] Prakash D, Nath P, Pal M. Composition, variation of nutritional contents in leaves, seed protein, fat and fatty acid profile of Chenopodium species. J Sci Food Agric 1993; 62(2): 203-205. https://doi.org/10.1002/jsfa.2740620214

[19] Sienera R. Oxalate contents of species of the Polygonaceae Amaranthaceae and Chenopodiaceae families. Food Chem 2006; 98(2): 220-224. https://doi.org/10.1016/j.foodchem.2005.05.059

Dhillon NPS, Monforte AJ, Pitrat M, et al. Melon landraces of India: contributions and importance. Plant Breed Rev 2012; 35: 85-150.

[21] Misra SK. Anti-nutritive bioactive compounds present in unconventional pulses and legumes. Res J Pharm Biol Chem Sci 2012; 3: 586-597.

[22] Barnard ND. Dr. Neal Barnard's Program for Reversing Diabetes. Rodale Inc., New York; 2007.

[23] WHO (World Health Organization). Diagnostic criteria and classification of hyperglycaemia first detected in pregnancy. World Health Organization, Report Number: WHO/NMH/MND/13.2. WHO, Geneva; 2013.

[24] Bourne RR, Stevens GA, White RA, et al. Causes of vision loss worldwide, 1990-2010: a systematic analysis. Lancet Global Health 2013; 1: e339-e349. https://doi.org/10.1016/S2214-109X(13)70113-X

[25] Bethesda MD. 2014 USRDS annual data report Epidemiology of kidney disease in the United States. United States Renal Data System. National Institutes of Health, National Institute of Diabetes and Digestive and Kidney Diseases 2014; p. 188-210.

[26] Sarwar N, Gao P, Seshasai SR, et al. Diabetes mellitus, fasting blood glucose concentration, and risk of vascular disease: a collaborative meta-analysis of 102 prospective studies. Emerging Risk Factors Collaboration. Lancet 2010; 26,375: 2215-2222.

[27] Humpel C. Chronic mild cerebrovascular dysfunction as a cause for Alzheimer's disease. Rev Exp Gerontol 2011; 46: 225-232.

https://doi.org/10.1016/j.exger.2010.11.032

[28] Humpel C. Editorial to the special issue "Vascular dementia". Rev Exp Gerontol 2012; 47: 1. https://doi.org/10.1016/j.exger.2012.10.001

[29] Monte SM. Type 3 diabetes is sporadic Alzheimer's disease: mini-review. Eur Neuropsychoparmacol 2014; 24: 19541060.

https://doi.org/10.1016/j.euroneuro.2014.06.008

[30] Heneka MT, Fink A and Doblhammer G. Effect of pioglitazone medication on the incidence of dementia. Annals Neurol 2015; 78: 284-294 https://doi.org/10.1002/ana.24439

[31] Klonoff DC. Continuous glucose monitoring: roadmap for 21st century diabetes therapy. Diabetes Care 2005; 28 : 1231-1239. https://doi.org/10.2337/diacare.28.5.1231

[32] Anderson JW, Deakins DA, Floore TL, et al. Dietary fiber and coronary heart disease. Crit Rev Food Sci Nutr 1990; 29: 95147.

https://doi.org/10.1080/10408399009527518

[33] Fuhrman J. The End of Diabetes: The Eat to Live Plan to Prevent and Reverse Diabetes. Harper Collins Publishers, New York; 2013 
[34] Carter P, Gray LJ, Troughton J, et al. Fruit and vegetable intake and incidence of type 2 diabetes mellitus: systematic review and meta-analysis. BMJ 2010; 341: c4229.

[35] Bazzano LA, Li TY, Joshipura KJ, et al. Intake of fruit, vegetables and fruit juices and risk of diabetes in women. Diabetes Care 2008; 31: 1311-1317. https://doi.org/10.2337/dc08-0080

[36] Khan BA, Abraham A, Leelamma S. Hypoglycemic action of Murraya Koeingii (curry leaf) and Brassica juncea (mustard): mechanism of action. Ind J Biochem Biophys 1995; 32: 106108.

[37] Pyoa YH, Lee TC, Logendrac L, et al. Antioxidant activity and phenolic compounds of Swiss chard (Beta vulgaris subspecies cycla) extracts. Food Chem 2004; 85: 19-26. https://doi.org/10.1016/S0308-8146(03)00294-2

[38] Bolkent S, Yanarda R, Tabakolu-Ouz A, et al. Effects of chard (Beta vulgaris L. var. cicla) extract on pancreatic B cells in streptozotocin-diabetic rats: a morphological and biochemical study. J Ethnopharmacol 2000; 73: 251-259. https://doi.org/10.1016/S0378-8741(00)00328-7

[39] Mateljan G. The World's healthiest foods. George Mateljan Foundation, Glendale, California; 2016.

[40] Tundis R, Loizzo MR, Menichini F. Natural products as alpha-amylase and alpha-glucosidase inhibitors and their hypoglycaemic potential in the treatment of diabetes: an update. Mini Rev Med Chem 2010; 10: 315-331. https://doi.org/10.2174/138955710791331007

[41] Kugler F, Stintzing FC, Carle R. Identification of betalains from petioles of differently colored Swiss chard (Beta vulgaris L. ssp. cicla [L.] Alef. Cv. Bright Lights) by high-performance liquid chromatography-electrospray ion. J Agric Food Chem 2004; 52: 2975-2981. https://doi.org/10.1021/jf035491w

[42] Yoshikawa M, Murakami T, Kadoya M, et al. Medicinal foodstuff III. Sugar beet. Hypoglicemic oleanolic acid oligoglycosides, betavulgarosides I, II, III, and IV from the root of Beta vulgaris L. (Chenopodiaceae). Chem Pharmaceut Bull 1996; 44: 1212-1217.

https://doi.org/10.1248/cpb.44.1212

[43] ADA (American Diabetes Association). Standards of Care. Diabetes Care 2016; 39 (Suppl. 1): S1-S119.

[44] Dias JS. Nutritional and health benefits of carrots and their seed extracts. Food Nutr Sci 2014; 5: 2147-2156. https://doi.org/10.4236/fns.2014.522227

[45] Coyne T, Ibiebele TI, Baade PD, et al. Diabetes Mellitus and serum carotenoids: findings of a population-based study in Queensland, Australia. Amer J Clinical Nutr 2005; 82: 685693.

[46] Poudyal H, Panchal S, Brown L. Comparison of purple carrot juice and $\beta$-carotene in a high-carbohydrate, high-fat diet-fed rat model of the metabolic syndrome. British J Nutr 2010; 104: $1322-1332$ https://doi.org/10.1017/S0007114510002308

[47] Swamy KRM, Nath P, Ahuja KG. 9. Vegetables for human nutrition and health. In: Nath $\mathrm{P}$, editor. The Basics of Human Civilization-Food, Agriculture and Humanity, Volume-II-Food. Prem Nath Agricultural Science Foundation (PNASF), Bangalore \& New India Publishing Agency (NIPA), New Delhi, India 2013. p. 145-198.
[48] Wang $\mathrm{H}$, Kruszewki A, Brautigan DL. Cellular chromium activation of insulin receptor kinase. Biochemistry 2005; 44: 8167-8175.

https://doi.org/10.1021/bi0473152

[49] Chen Q, Chan LLY, Li ETS. Bitter melon (Momordica charantia) reduces adiposity, lowers serum insulin and normalizes glucose tolerance in rats fed a high fat diet. $\mathrm{J}$ Nutr 2003; 133: 1088-1093.

[50] Patil B, Jayaprakasha GK and Vikram A. Indigenous crops of Asia and Southeast Asia: exploring health-promoting properties. HortScience 2012; 47: 821-827.

[51] Chao PM. One more support for recruiting bitter melon in therapeutic diet for diabetes and its comorbidity management - bitter melon ameliorates hepatic steatosis related with hyperglycemia. BIT's 4th Annual World Congress of Diabetes - 2015, Kaohsiung, Taiwan. 2015; p. 236.

[52] Ahmad N, Hassan M, Halder H, Bennoor K. Effect of Momordica charantia (Karolla) extracts on fasting and postprandial serum glucose levels in NIDDM patients. Bangladesh Med Res Counc Bull 1999; 25:11.

[53] Yeh G, Eisenberg D, Kaptchuk T, Phillips R. Systematic review of herbs and dietary supplements for glycemic control in diabetes. Diabetes Care 2003; 26: 1277. https://doi.org/10.2337/diacare.26.4.1277

[54] Chen J, Tian R, Qiu M, et al. Trinorcucurbitane and cucurbitane triterpenoids from the roots of Momordica charantia. Phytochemistry 2008; 69: 1043-1048. https://doi.org/10.1016/i.phytochem.2007.10.020

[55] Saxena A, Vikram N. Role of selected Indian plants in management of type 2 diabetes: A review. J Alternative Comp Med 2004; 10: 369-378. https://doi.org/10.1089/107555304323062365

[56] Singh LW. Traditional medicinal plants of Manipur as antidiabetics. J Med Plants Res 2011; 5: 677-687.

[57] Villegas R, Gao YT, Yang G, et al. Legume and soy food intake and the incidence of type 2 diabetes in the Shanghai women's health study. Am J Clin Nutr 2008; 87: 162-167.

[58] Imai S, Fukui M, Kajiyama S. Effect of eating vegetables before carbohydrates on glucose excursions in patients with type 2 diabetes. J Clin Biochem Nutr 2014; 54: 7-11. https://doi.org/10.3164/jcbn.13-67

[59] Imai S, Fukui M, Ozasa N, et al. Eating vegetables before carbohydrates improves postprandial glucose excursions. Diabet Med 2013; 30: 370-372. https://doi.org/10.1111/dme.12073

[60] Imai S, Fukui M, Kajiyama S. Food order as a significant impact on postprandial glucose and insulin levels. Diabetes Care 2015; 38: e98-e99. https://doi.org/10.2337/dc15-0429

[61] Wong JM, Jenkins DJ. Carbohydrates digestibility and metabolic effects. J Nutr 2007; 137: S2539-S2546.

[62] Ma J, Stevens JE, Cukier K, et al. Effects of a protein preload on gastric emptying, glycemia, and gut hormones after a carbohydrate meal in diet-controlled type 2 diabetes. Diabetes Care 2009; 32: 1600-1602. https://doi.org/10.2337/dc09-0723 